\title{
Insulin action and determinants of glycaemia in a rat model of Type 2 (non-insulin-dependent) diabetes mellitus
}

\author{
W. S. Pascoe, A. B. Jenkins, M. Kusumoki and L. H.Storlien \\ Garvan Institute of Medical Research, St. Vincent's Hospital, Sydney, Australia
}

\begin{abstract}
Summary. We aimed to assess prandial responses, basal glucose turnover and insulin action (euglycaemic clamp) in a very low-dose neonatal streptozotocin model of Type 2 (noninsulin-dependent) diabetes mellitus. Male Wistar rats were injected at 2 days of age with $45 \mathrm{mg} / \mathrm{kg}$ streptozotocin or vehicle (control). At 8 weeks, the groups were subdivided and fed either a high-fat or high-starch diet for 3 weeks. Both the fat diet and streptozotocin treatments had independent hyperglycaemic effects (streptozotocin/fat $9.3 \pm 0.3 \mathrm{mmol} / \mathrm{l}$; streptozotocin/starch $7.5 \pm 0.3 \mathrm{mmol} / \mathrm{l}$; control/fat $7.4 \pm 0.1$ $\mathrm{mmol} / \mathrm{l}$; all $p<0.01 \mathrm{vs}$ control/starch $6.4 \pm 0.1 \mathrm{mmol} / \mathrm{l})$. The fat diet effect was associated with both a reduction in basal glucose clearance $(p<0.001)$ and in basal hepatic glucose output $(p<0.05)$. Streptozotocin increased basal hepatic glucose output. Significantly higher prandial glycaemia in the streptozotocin/starch group occurred despite similar insulin
\end{abstract}

levels and appeared to be related to an impaired early insulin response. Whole-body and tissue-specific insulin sensitivity were significantly depressed in fat-fed animals compared to starch-fed animals, however there were no significant effects of streptozotocin treatment. We conclude that fasting hyperglycaemia associated with abnormalities in both glucose production and clearance can exist in the presence of a basal hepatic glucose output which is reduced compared to control animals. Furthermore, dietary-fat-induced insulin resistance is not exacerbated by the relative insulin deficiency and/or mild hyperglycaemia observed when dietary fat and neonatal streptozotocin-treatments are combined.

Key words: Rat, basal hyperglycaemia, insulin action, Type 2 (non-insulin-dependent) diabetes mellitus.
A rat model that displays some of the pathophysiology of Type 2 (non-insulin-dependent) diabetes mellitus can be produced by neonatal injection of a low dose $(45 \mathrm{mg} / \mathrm{kg})$ of streptozotocin (STZ) combined with later introduction of a high-fat diet [1]. Until 8 weeks of age on a chow diet, rats are normoglycaemic. Basal hyperglycaemia, glucose intolerance and a specific attenuation of acute insulin reponse to intravenous glucose may then be induced by 3 weeks of high-fat feeding ( $59 \%$ of calories as safflower oil). These defects are similar to those present in many individuals with Type 2 diabetes [2-5] and are also similar to those obtained in the high dose $(100 \mathrm{mg} / \mathrm{kg})$ neonatal STZ model developed by Portha and associates in 1979 [6]. The critical difference between the high-dose model, which has subsequently been extensively characterized in the laboratories of both Portha and Weir, and the current model, is not only the much lower dose of STZ but, perhaps more importantly, the diet-dependency. That is, all animals, both STZ and control, are normoglycaemic and normoinsulinaemic until they are subdivided and fed a diet either high in fat or high in starch content. Only those animals which are both STZ-treated and high-fat-fed become notably hyperglycaemic. In addition they remain normoinsulinaemic in the absolute sense. This combination of treatments may be particularly useful for the study of the interaction between insulin secretory defects, insulin resistance and mild basal hyperglycaemia which results when these factors are combined. The aim of the current study was to further characterize this model by direct assessment of the postprandial metabolic profile and of in vivo glucose turnover and insulin sensitivity. More specifically, this study was aimed at elucidating a mechanism for the observed basal hyperglycaemia and further, to investigate the effect of hyperglycaemia and/or relative insulin deficiency on insulin sensitivity.

\section{Materials and methods}

\section{Animals}

All experiments reported herein were approved by the Garvan Institute Animal Experimentation Ethics Committee and comply with the National Health and Medical Research Council of Australia gui- 
delines for Care and Use of Animals for Research Purposes. This study was carried out on male Wistar rats bred in the Garvan Institute Biological Testing Facility. Two days after birth, pups received streptozotocin (STZ, $45 \mathrm{mg} / \mathrm{kg}$ ) (Sigma, St. Louis, Mo., USA) in $50 \mu \mathrm{l}$ citrate buffer $(0.1 \mathrm{~mol} / \mathrm{l}, \mathrm{pH} 4.5)$ i. p. Control litters received citrate buffer only. All litters were limited to eight pups and remained with their mothers until weaning at 4 weeks of age. The animals were maintained at $21 \pm 1^{\circ} \mathrm{C}$ on a $12 / 12 \mathrm{~h} \mathrm{light/dark} \mathrm{cycle} \mathrm{and}$ after weaning were allowed access to commercial rat chow (Allied Feeds, Sydney, Australia) and water ad libitum.

\section{Diets}

At 8 weeks of age, control and STZ-treated animals were randomly assigned to either a high-starch or high-fat diet, thus generating four groups: STZ/fat, STZ/starch, control/fat and control/starch. The composition of the diets were as previously reported [1] with $69 \%$ carbohydrate and 10\% fat (by calories) in the "starch" diet and 59\% fat and $20 \%$ carbohydrate in the "fat" diet. These were made freshly every 3 to 4 days and were stored at $4^{\circ} \mathrm{C}$. Rats were fed isocaloric amounts of diet ( $311 \mathrm{~kJ} /$ day), spillage being collected and its weight added to the following days intake. Usually rats spilled only on the first one to two days of the diet. The animals were fed in small metal bowls just prior to the beginning of the dark cycle. Rats were maintained on fat or starch diets for 3 weeks.

\section{Prandial responses}

Following 3 weeks on experimental diets, the four groups of rats ( $n=5$ or 6 in each case) were studied for their circulating basal and prandial insulin, glucose, non-esterified fatty acid (NEFA) and triglyceride levels. Empty food dishes were removed 3 h into the light period and a basal blood sample $(-250 \mu \mathrm{l})$ was taken $6-7 \mathrm{~h}$ later. The rats' normal diet was then given within $30 \mathrm{~min}$ of lights off and blood samples $(\sim 250 \mu \mathrm{l})$ were taken $30 \mathrm{~min}$ and $1,2,4,7$, and $10 \mathrm{~h}$ later. Food intake was measured at each time point. All rats had been extensively gentled by repeated handling during the 3-week feeding period and blood samples were obtained from the cut tip of the tail following warming in $45^{\circ} \mathrm{C}$ water. Serum was stored at $-20^{\circ} \mathrm{C}$ for later analysis.

\section{Surgery (euglycaemic clamp rats)}

Rats were anaesthetized using sodium pentobarbitone (Bomac Laboratories, Asquith, Australia; $20 \mathrm{mg} / \mathrm{kg}$ i.p.) and ketamine hydrochloride (Parke-Davis, Caringbah, Australia; $50 \mathrm{mg} / \mathrm{kg}$ i.p.). Silastic cannulae $(0.025$ inch internal diameter $\times 0.047$ inch outer diameter, \# 602-155;0.020 inch internal diameter $\times 0.037$ inch outer diameter, \# 602-135, Dow Corning, Midland, Mich., USA) were inserted into the left external jugular vein and the right carotid artery, respectively. Both cannulae were exteriorized dorsally - the jugular line was filled with heparinized $154 \mathrm{mmol} / 1 \mathrm{NaCl}$ (saline) $(10 \mathrm{IU} / \mathrm{ml})$ and capped and the carotid line was filled with a $60 \%$ solution of polyvinylpyrrolidone $\mathrm{K} 30\left(\mathrm{M}_{\mathrm{r}}\right.$ approx. 40000 , Fluka $\mathrm{AG}$, Bioscientific, Australia $)$ in heparinized saline $(1000 \mathrm{IU} / \mathrm{ml})$ and capped. Animals were allowed to recover for at least 2 days prior to experimentation. Food intake in the post-operative recovery period was $70-100 \%$ of normal and did not differ between groups.

\section{Study 1 -euglycaemic clamp}

On the morning of the study, rats were deprived of food for $5 \mathrm{~h}$. Long sampling lines were attached to the cannulae and the animals were allowed to settle for at least $30 \mathrm{~min}$ prior to experimentation. A
$600 \mu$ basal blood sample was taken for determination of blood glucose, plasma glucose and plasma insulin. The clamp procedure was then undertaken as previously described [7]. Blood glucose concentration was measured using an immobilized glucose-oxidase method (model 23AM Glucose Analyser, Yellow Springs Instrument Co., Yellow Springs, Ohio, USA). Plasma was stored at $-20^{\circ} \mathrm{C}$ for later assay. Resuspended erythrocytes were returned to the animal and a combined infusion of $30 \%$ glucose solution ( $50 \%$ weight/volume solution, David Bull Laboratories, Australia) and porcine insulin (Actrapid neutral insulin injection, $100 \mathrm{U} / \mathrm{ml}$; Commonwealth Serum Laboratories-Novo, North Rocks, New South Wales, Australia) was commenced via the arterial line. Insulin was infused at a rate of $0.25 \mathrm{U} \cdot \mathrm{kg}^{-1} \cdot \mathrm{h}^{-1}$ for approximately $2 \mathrm{~h}$ to achieve a plasma insulin concentration in the mid- to upper-physiological range $(\approx 700$ $\mathrm{pmol} / \mathrm{l}$ ). Glucose was infused at a variable rate to maintain euglycaemia. All animals were clamped at normoglycaemia (plasma glucose; STZ/fat, $6.4 \pm 0.2 \mathrm{mmol} / \mathrm{l}$; STZ/starch, $6.3 \pm 0.2 \mathrm{mmol} / \mathrm{l}$; control/fat, $6.6 \pm 0.2 \mathrm{mmol} / 1$; control/starch, $6.3 \pm 0.3 \mathrm{mmol} / \mathrm{l}$ ). Samples for blood glucose determination of $25 \mu \mathrm{I}$ were taken at 5-10 min intervals. At an average of $90 \pm 2$ min after commencement of the study a $400 \mu \mathrm{l}$ blood sample for glucose and insulin determination was taken and then a combined bolus of $\mathrm{D}-\left[\mathrm{U}-{ }^{14} \mathrm{C}\right]$-glucose $(50 \mu \mathrm{Ci}$; Amersham, Amersham, Bucks., UK) and the glucose analogue 2,6$\left[{ }^{3} \mathrm{H}\right]$-2-deoxy-D-glucose $\left(\left[{ }^{3} \mathrm{H}\right]-2 \mathrm{DG}\right)(80 \mu \mathrm{Ci} ;$ Amersham $)$ was administered via the veneous cannula. The cannula was flushed thoroughly using the resuspended erythrocytes and physiological saline. Blood samples of $150 \mu \mathrm{l}$ were obtained 2, 5, 10, 15, 20 and $30 \mathrm{~min}$ after the administration of the bolus for estimation of plasma glucose concentration and plasma tracer concentration. Plasma samples of $50 \mu \mathrm{l}$ were deproteinized immediately in $5.5 \% \mathrm{ZnSO}_{4}$ and saturated $\mathrm{Ba}(\mathrm{OH})_{2}$.

At the completion of the clamp a $600 \mu \mathrm{l}$ blood sample was taken for determination of final plasma insulin, glucose and tracer concentration. The animals were rapidly anaesthetized $(100 \mathrm{mg} / \mathrm{kg}$ i. v. pentobarbitone) and the following tissues were rapidly removed and freeze-clamped using aluminium tongs pre-cooled in liquid nitrogen: soleus, plantaris, red gastrocnemius, white gastrocnemius, extensor digitorum longus, white quadriceps, red quadriceps, liver, diaphragm, lung, heart, subcutaneous white adipose tissue, epididymal white adipose tissue, inguinal white adipose tissue and interscapular brown adipose tissue. Excised tissues were stored at $-70^{\circ} \mathrm{C}$ for later assay.

\section{Study 2 - steady-state glucose turnover}

Steady-state glucose turnover was measured during a euglycaemic clamp by the isotope dilution method [8]. This involved a primed continuous infusion of D-3- $\left[{ }^{3} \mathrm{H}\right]$-glucose in the basal state and then in combination with a euglycaemic clamp. The D-3-[ $\left.{ }^{3} \mathrm{H}\right]$-glucose (Amersham) was purified prior to use by thin layer chromatography on silica plates $(20 \times 20 \mathrm{~cm}, 0.2 \mathrm{~mm}$ layer; Merck, Darmstadt, FRG) [9]. Non-volatile ${ }^{3} \mathrm{H}$-labelled material isolated from rat plasma obtained after the glucose clamp procedure described below, contained $95 \pm 2 \%(n=13)$ yeast hexokinase reactive material, not significantly different from the infusates $(96 \pm 1 \%, n=6)$ indicating no progressive accumulation of contaminants.

On the morning of the study, rats were deprived of food for $5 \mathrm{~h}$. Long sampling lines were attached and the animals were allowed at least $30 \mathrm{~min}$ to settle. A $600 \mu \mathrm{l}$ basal blood sample was then taken for determination of plasma glucose and insulin and serum NEFA. The resuspended erythrocytes were returned with the priming dose. The priming dose was $1.25 \mu \mathrm{Ci}$ and the continuous infusion was delivered at a rate of $0.05 \mu \mathrm{Ci} / \mathrm{min}$. In the basal state, tracer steady state was not achieved in all animals after $90 \mathrm{~min}$ and basal glucose turnover was therefore measured in separate groups of animals (see Study 3 below). After 90 min, a hyperinsulinaemic euglycaemic clamp as described above (Study 1) was initiated and continued for at least 90 min during which steady-state tracer and plasma glucose concentrations were attained. Three $200 \mu 1$ blood samples were taken at 
10 -min intervals at the end of the clamp period. At $90 \mathrm{~min}$, a $600 \mu \mathrm{l}$ sample was taken for determination of plasma glucose specific activity and plasma insulin concentration. Resuspended erythrocytes were returned to the animal before the clamp procedure was commenced. In the insulin-stimulated state, D-3- $\left[{ }^{3} \mathrm{H}\right]$-glucose, porcine insulin and $30 \%$ glucose solution were infused simultaneously for at least $90 \mathrm{~min}$ or until euglycaemia was achieved. Three $250 \mu \mathrm{l}$ blood samples were taken $10 \mathrm{~min}$ apart during that period when both steady-state radioactivity and euglycaemia had been achieved. All animals were clamped at normoglycaemia (plasma glucose; STZ/fat, $6.4 \pm 0.4 \mathrm{mmol} / \mathrm{l} ; \mathrm{STZ} / \mathrm{starch}, 6.9 \pm 0.1 \mathrm{mmol} / \mathrm{l}$; control/fat, $6.6 \pm$ $0.2 \mathrm{mmol} / 1$; control/starch, $6.5 \pm 0.2 \mathrm{mmol} / \mathrm{l})$. Plasma insulin concentrations in the mid- to upper-physiological range were achieved $(732 \pm 50 \mathrm{pmol} / \mathrm{l})$. All samples for determination of plasma radioactivity were centrifuged immediately and 75-100 $\mu$ l of plasma was deproteinized using $5.5 \% \mathrm{ZnSO}_{4}$ and saturated $\mathrm{Ba}(\mathrm{OH})_{2}$. An aliquot of supernatant was dried down to remove $\left[{ }^{3} \mathrm{H}\right]-\mathrm{H}_{2} \mathrm{O}$ prior to counting in a liquid scintillation spectrometer (Beckman Instruments, Fullerton, Calif., USA). A $600 \mu$ l blood sample was obtained at the conclusion of the experiment for determination of plasma glucose specific activity and plasma insulin. Blood was centrifuged immediately and samples stored at $-20^{\circ} \mathrm{C}$ until assayed.

\section{Study 3 - basal glucose turnover}

Glucose turnover in the basal state was measured using a bolus injection of $3-\left[{ }^{3} \mathrm{H}\right]$-glucose. On the morning of the study, animals were deprived of food for $5 \mathrm{~h}$, attached to long sampling lines and allowed to settle for at least $30 \mathrm{~min}$. A systemic bolus of $80 \mu \mathrm{Ci} 3-\left[{ }^{3} \mathrm{H}\right]$ glucose was delivered at $t=0$, and $150 \mu \mathrm{l}$ blood samples for glucose and $\left[{ }^{3} \mathrm{H}\right]$ glucose determination were obtained at $2,5,10,15,20,30$ and $45 \mathrm{~min} .\left[{ }^{3} \mathrm{H}\right]$-glucose in plasma was determined as described for Study 2 . The $\left[{ }^{3} \mathrm{H}\right]$-glucose plasma time course was fitted to a double exponential function and steady-state glucose turnover was calculated for the extrapolated area to infinity under the disappearance curve using standard methods [7].

\section{Analytical methods}

Immunoreactive insulin concentrations in plasma were assessed by the double antibody radioimmunoassay method of Morgan and Lazarow [10] against a rat insulin standard (Novo-Nordisk, Bagsvaerd, Denmark). Serum NEFA was measured using the Wako Nefa C kit (Wako Chemicais, Osaka, Japan).

Tissue-specific glucose metabolic index ( $\left.\mathrm{Rg}^{\prime}\right)$ was measured as follows: frozen tissues were diluted approximately 1:10 with distilled water and homogenized. Homogenates were centrifuged and $200 \mu \mathrm{l}$ aliquots of supernatant were passed through AG1-X8 100-200 mesh acetate form resin minicolumns (Biorad, Richmond, Calif., USA) to bind phosphorylated $\left[{ }^{3} \mathrm{H}\right]-2 \mathrm{DG}$. Columns were washed five times with $500 \mu 1$ distilled water. Unphosphorylated and total $\left[{ }^{3} \mathrm{H}\right]-2 \mathrm{DG}$ counts were obtained by liquid scintillation spectrometry (Beckman Instruments). The amounts of phosphorylated $\left[{ }^{3} \mathrm{H}\right]-2 \mathrm{DG}$ trapped in the tissue may be derived by subtracting the unphosphorylated from the total counts.

\section{Calculations}

Steady-state glucose turnover: In the steady-state, glucose disappearance rate $(\mathrm{Rd})$ can be calculated as $\mathrm{Rd}^{*} / \mathrm{SAg}$ where, $\mathrm{Rd}^{*}$ is tracer infusion rate $(\mathrm{dpm} / \mathrm{min})$ and SAg is steady-state plasma glucose specific activity $(\mathrm{dpm} / \mathrm{ml})$.

In the basal state, systemic glucose disappearance rate (Rd) is equal to systemic glucose appearance rate ( $\mathrm{Ra}$ ). Glucose clearance rate is calculated as Ra/basal plasma glucose concentration. In the insulin-stimulated state, $\mathrm{Ra}$ is calculated as $\mathrm{Rd}$ minus GIR where
GIR is the glucose infusion rate during the steady-state part of the euglycaemic clamp and provides a measure of whole-body insulin sensitivity.

Tissue-specific glucose uptake: The glucose metabolic index ( $\mathrm{Rg}^{\prime}$ ) is calculated in individual tissues from the measurement of the tissue accumulation of phosphorylated $\left[{ }^{3} \mathrm{H}\right]-2 \mathrm{DG}$, the time course of plasma $\left[{ }^{3} \mathrm{H}\right]-2 \mathrm{DG}$ disappearance and the plasma glucose concentration. The mathematical treatment of this concept and the required assumptions have been adequately discussed in previous studies [7].

\section{Statistical analysis}

All results are expressed as mean \pm SEM. Data were initially analysed using two-way analysis of variance with diet (starch/fat) and with treatment (control/STZ) as main effects. Selected data with significant main effects were subjected to post-hoc one-way planned comparisons between groups (control/starch, control/fat, STZ/starch and STZ/fat groups) using a Scheffe F-test (Statview $512+$, Abacus Concepts/Brainpower Inc., Calabassas, Calif., USA).

\section{Results}

Table 1 shows the body weight, basal plasma glucose and insulin concentrations in control and STZ-treated animals after 3 weeks of either fat or starch diets. Although the diets were isocaloric, fat-fed animals were $9 \%$ heavier than their starch-fed counterparts. This may be due to the reduction of thermogenic capacity induced by fat-feeding [11] or to spillage of diet by starch-fed animals, although this effect was minimized by taking the food equivalent of the spilled food weight and adding it to the following days intake. Both high-fat diet and STZ treatment had independent effects on basal plasma glucose concentration (Table 1). All post-hoc pair-wise comparisons between groups were significant $(p<0.05)$ except for STZ/starch vs control/fat. The effect of the various treatments on basal plasma insulin is shown in Table 1. Neither diet nor STZ treatment showed significant independent effects on serum insulin, but there was a significant interaction between the two treatments (Table 1 ) reflected in the isolated elevation seen in the control/fat group ( $p<0.05$ vs each of the other three groups, F-test). The relationship between the basal insulin and glucose concentrations is seen in Figure 1. Within the control animals (control/starch and control/fat) there was a significant positive relationship between circulating glucose and insulin $(r=0.55, p<0.005)$. No such relationship was seen within the STZ-treated animals $(r=0.14, \mathrm{NS})$.

Figure 2 shows the temporal pattern of food intake. Intake is expressed as percent of total calories and since the starch and fat diets were given in isocaloric amounts, it can be seen that all groups were consuming calories at approximately the same rate and almost all food was eaten over the 10 -h measurement period. Figure 3 shows the serum glucose and insulin responses. Both control groups maintained postprandial serum glucose levels within $0.5 \mathrm{mmol} / \mathrm{l}$ of basal values. The peak insulin responses of these groups were similar but the control/starch group apparently handled the greater carbohydrate load by a much larger early insulin response. The increment in serum insulin level by $30 \mathrm{~min}$ in the control/starch group was 
Table 1. Glycaemia, serum insulin, and glucose turnover in the basal state and during the hyperinsulinaemic euglycaemic clamp

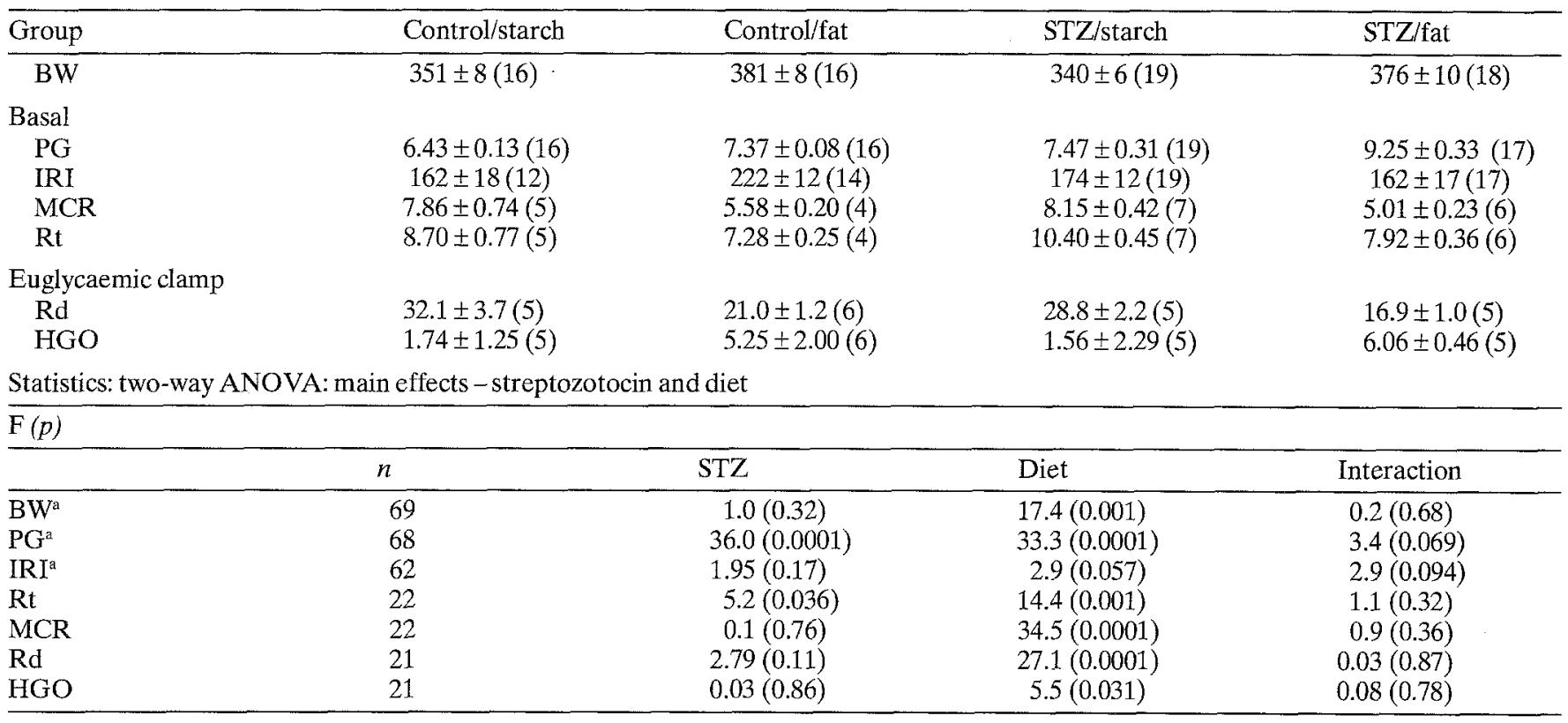

a combined data from Studies 1,2 and 3. Abbreviations: STZ (streptozotocin treatment); BW (body weight, g); PG (basal plasma glucose, $\mathrm{mmol} / \mathrm{l}$ ); IRI (basal immunoreactive plasma insulin, $\mathrm{pmol} / \mathrm{l}$ ); MCR (metabolic clearance rate, $\mathrm{ml} \cdot \mathrm{kg}^{-1} \cdot \mathrm{min}^{-1}$ ); Rt (rate of turn-

$280 \mathrm{pmol} / 1$ compared to 70 to $110 \mathrm{pmol} / 1$ in the other three groups $(p<0.01)$. The basal hyperglycaemia of the STZ/fat group was maintained throughout with a small early, and reduced total, insulin response compared to other groups. The STZ/starch group displayed a large and prolonged postprandial glycaemic excursion with an increase of $\sim 2.5 \mathrm{mmol} / \mathrm{l}$. Compared to the control/starch group, the insulin response in the STZ/starch group was sluggish and inappropriately low in relation to the hyperglycaemia. However, the total area of the insulin increment was similar between these groups over the $10 \mathrm{~h}$ of feeding.

Figure 4 shows the basal and prandial serum triglyceride and NEFA values. Triglyceride levels were persistently higher $(p<0.05$, two-way ANOVA) in the fat-fed groups and, within diet conditions, hypertriglyceridaemia was exacerbated by STZ treatment. Basal NEFA values

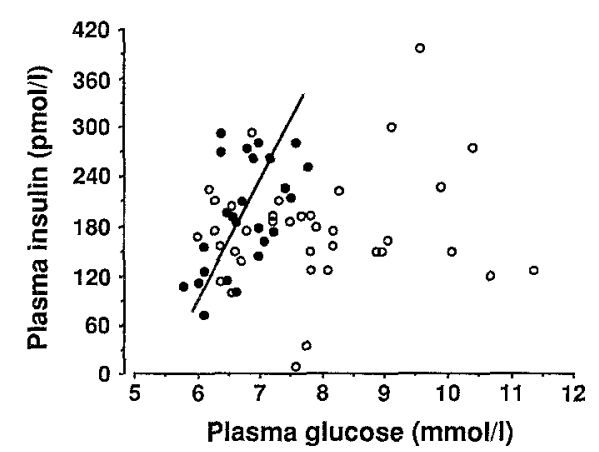

Fig. 1. Relationship between fasting plasma insulin and glucose concentrations in control (fat- and starch-fed, -) and streptozotocintreated (fat- and starch-fed, $O$ ) animals. The regression line is shown for the control animals only (simple regression $r=0.55$, $p<0.001$ ) over, $\mathrm{mg} \cdot \mathrm{kg}^{-1} \cdot \mathrm{min}^{-1}$ ); Rd (rate of glucose disposal, $\mathrm{mg} \cdot \mathrm{kg}^{-1}$. $\mathrm{min}^{-1}$ ); HGO (hepatic glucose output, $\mathrm{mg} \cdot \mathrm{kg}^{-1} \cdot \mathrm{min}^{-1}$ ); F (p) (distribution and probability of occurrence determined by ANOVA). Mean $\pm \operatorname{SEM}(n)$

were significantly lower in the fat-fed groups $(p<0.05)$ but in response to feeding NEFA values dropped by about $50 \%$ in both starch-fed groups in contrast to a three-fold increase in both fat-fed groups. No effect of STZ per se could be detected.

Figure 5 shows whole-body insulin sensitivity in STZ and control animals fed fat or starch diets as assessed by the rate of glucose infusion required to maintain euglycaemia during a glucose clamp. A significant difference $(p<0.01)$ was observed between fat- and starch-fed animals; fat-fed animals showing a marked diminution of insulin sensitivity. No difference was observed, however, between control and STZ animals within each diet group.

The glucose metabolic index ( $\left.\mathrm{Rg}^{\prime}\right)$ in an average of nine muscles (soleus, plantaris, red and white quadriceps, red and white gastrocnemius, extensor digitorum longus, heart and diaphragm) and an average of four adipose tis-

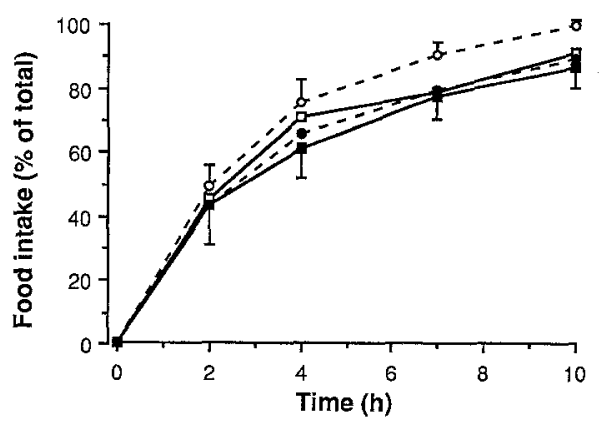

Fig.2. Food intake (as \% of calories) over the $10 \mathrm{~h}$ after food presentation for the four experimental groups $(\square-\square$, control/starch; $\bigcirc---O$, control/fat; - - , streptozotocin (STZ)/starch; --.- , STZ/fat; error bars are SEM). Food was presented in equicaloric amounts within $30 \mathrm{~min}$ of lights off and any spillage was added back at each weighing 

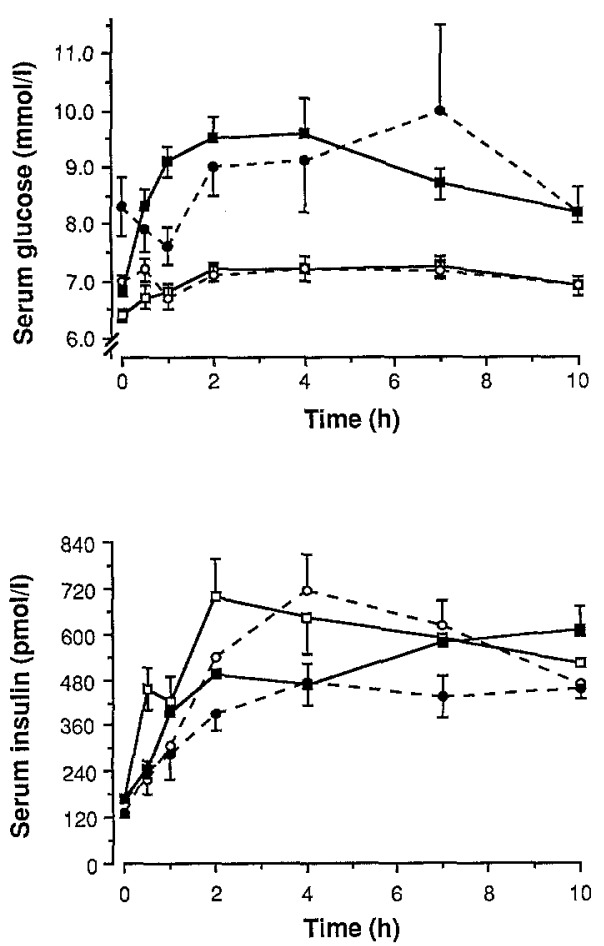

Fig.3. Serum glucose and insulin levels ( \pm SEM) basally, and for the $10 \mathrm{~h}$ of feeding shown in Figure 2. $n=5$ or 6 at each time point. $\square-\square$, control/starch; O- O, control/fat; $-\mathbf{-}$, streptozotocin (STZ)/starch; $\bullet-$, STZ/fat

sues (white adipose: subcutaneous, inguinal and epididymal; brown adipose: interscapular) are shown in Figure 6. Results are expressed as a percent of the average value for the control/starch group. Fat-feeding significantly reduced mean Rg' $(p<0.01)$ to about $70 \%$ of starch-fed values in muscle and to about $20 \%$ of starch-fed values in adipose tissue. There was no effect of STZ-treatment on tissue glucose utilization. Rg' values in individual muscle and adipose tissues are given in Table 2.

Glucose turnover in the basal state (Study 3, bolus method) is shown in Table 1. Two-way ANOVA of basal glucose turnover data showed significant and non-interacting effects of diet (decrease, $p=0.001$ ) and STZ treatment (increase, $p<0.05$ ) on the rate of turnover $(\mathrm{Rt})$. Basal metabolic clearance rate (MCR) was suppressed by the high-fat diet $(p=0.0001)$ but was not affected by STZ treatment. These independent effects of diet and STZ treatment are seen most clearly in Figure 7 where basal plasma glucose and glucose turnover data are presented as percentages of the respective values in the control/starch group. Fat diet alone and STZ alone had virtually identical effects on plasma glucose. With the fat diet treatment, the plasma glucose elevation is clearly associated with a reduced glucose clearance; hepatic glucose output (HGO) is reduced. In contrast, the hyperglycaemic effect of STZ is clearly associated with an elevated HGO and unchanged clearance. The two treatments combined resulted in a more marked hyperglycaemia associated with a markedly reduced clearance of glucose and an inappropriately high (although still less than control) HGO.

The effects on basal glucose turnover seen in Study 3 (bolus method), and described in the above paragraph, were not apparent in the data derived from the basal period of Study 2 (primed infusion method). In Study 2 neither basal MCR (control/starch $9.2 \pm 1.0 \mathrm{mg} \cdot \mathrm{kg}^{-1}$. $\mathrm{min}^{-1}$; control/fat $7.1 \pm 0.4 \mathrm{mg} \cdot \mathrm{kg}^{-1} \cdot \mathrm{min}^{-1} ; \mathrm{STZ} / \mathrm{starch}$ $7.3 \pm 0.6 \mathrm{mg} \cdot \mathrm{kg}^{-1} \cdot \mathrm{min}^{-1} ; \quad$ STZ/fat $\quad 6.8 \pm 0.7 \mathrm{mg} \cdot \mathrm{kg}^{-1}$. $\left.\mathrm{min}^{-1}\right)$ nor rate of glucose turnover $\left(10.7 \pm 1.1 \mathrm{mg} \cdot \mathrm{kg}^{-1}\right.$. $\min ^{-1} ; 9.0 \pm 0.4 ; 8.9 \pm 0.7 ; 10.3 \pm 0.9$, respectively) were significantly affected by diet or STZ treatment.

Glucose turnover under hyperinsulinaemic conditions is also shown in Table 1. The high fat diet was associated with elevated HGO $(p<0.05)$ and decreased $\mathrm{Rd}$ $(p<0.001)$ and MCR $(p<0.001)$ but streptozotocin treatment did not affect any glucose turnover parameter under hyperinsulinaemic conditions.

\section{Discussion}

These studies confirm that the consumption of diets with a high omega-6 unsaturated fat content will induce insulin resistance in rats. Loss of insulin sensitivity at the wholebody level was associated with reduced sensitivity in the liver and in individual peripheral muscle and adipose tissues. The present observations are thus in agreement with earlier euglycaemic clamp studies [11]. At the whole-body level, all fat-fed rats displayed the same degree of insulin resistance despite the fact that STZ/fat rats were hyperglycaemic and relatively insulin deficient compared to control/fat rats. Similarly, both control and STZ starch-fed rats displayed a similar sensitivity to insulin despite the persistent, marked prandial hyperglycaemia displayed by this latter group. Similar to the whole-body results, there
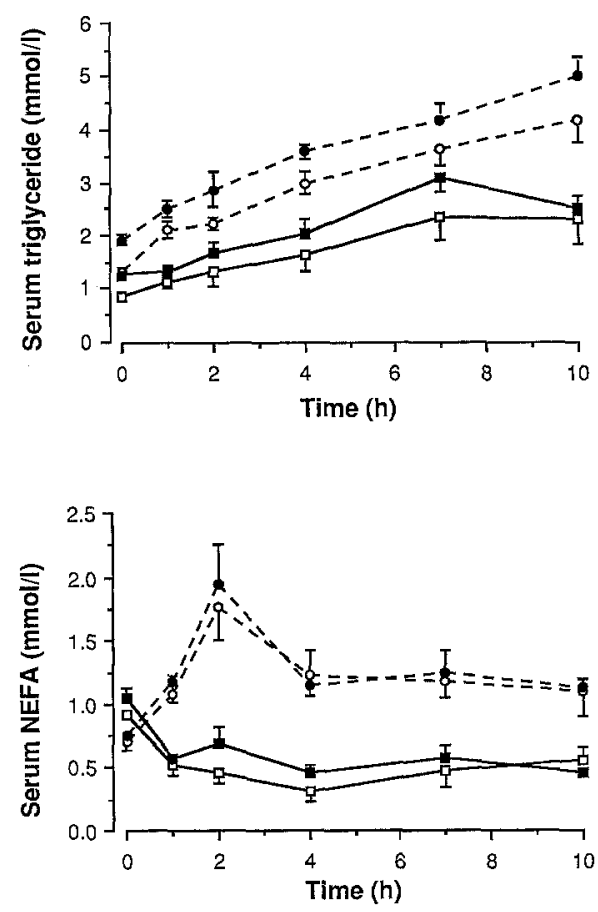

Fig.4. Serum triglyceride and non-esterified fatty acid (NEFA) levels basally, and for the $10 \mathrm{~h}$ of feeding shown in Figure $2 . n=5$ or 6

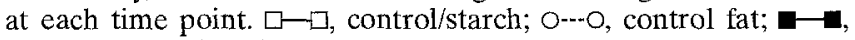
streptozotocin (STZ)/starch; •--•, STZ/fat 


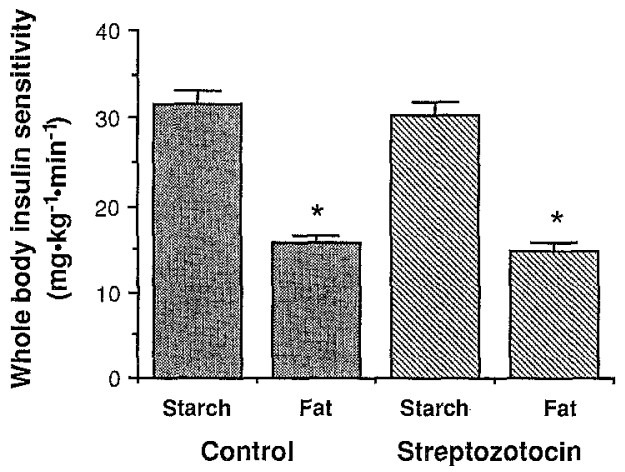

Fig.5. Whole-body insulin sensitivity in streptozotocin (STZ) and control animals fed fat or starch diets as assessed by the rate of glucose infusion required to maintain euglycaemia during a glucose clamp. Control/starch, $n=18$; Control/fat, $n=20 ; \mathrm{STZ} /$ starch, $n=21 ;$ STZ/fat, $n=17$. $* p<0.001$ compared to starch-fed

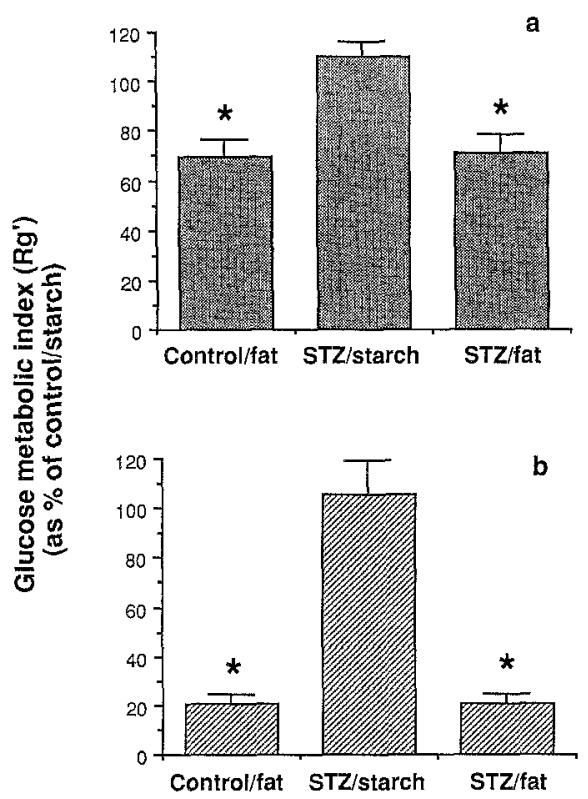

Fig. 6a,b. The glucose metabolic index ( $\left.\mathrm{Rg}^{\prime}\right)$ in a an average of nine muscles and $\mathbf{b}$ an average of four adipose tissues. Results are expressed as a percent of the average value for the control/starch group. Control/starch, $n=6$; control/fat, $n=6$; streptozotocin (STZ)/starch, $n=7 ;$ STZ/fat, $n=5$. * $p<0.01$ compared to starchfed

was a significant diet effect but no interaction between diet and STZ treatment at the level of the liver. In both control/starch and STZ/starch groups insulin suppressed liver glucose output appropriately and equivalently (86 and $89 \%$, respectively). Fat-feeding impaired this response, again equivalently, in the control/fat and STZ/fat groups ( 41 and $38 \%$ suppression, respectively). These results can then be compared to those where a high dose $(100 \mathrm{mg} / \mathrm{kg})$ of STZ on the day of birth was used to produce a persistently hyperglycaemic rat [6]. Clamp studies in these animals demonstrated an unchanged insulinstimulated glucose uptake in peripheral tissues and even a paradoxically enhanced sensitivity to insulin's suppressive effect on hepatic glucose production [12]. Taken together with the results of the current studies (both within-diet effects), these studies argue against a role for modest hyper- glycaemia and/or relative insulin deficiency in the development of insulin resistance.

The significant fat diet-induced reduction of basal glucose turnover is an unexpected finding in this study, probably obscured in previous studies [11] by bias in the primed infusion method used for measuring basal glucose turnover. This bias can result from a failure to reach steady-state due to inappropriate choice of a priming dose, the choice of which is dependent upon a knowledge of the rate of turnover to be measured [13,14]. Consistent with this, the strong effects of diet and STZ treatment seen in Study 3 were not apparent in the basal period of the primed infusion method study (Study 2). Most consistent with this finding would be a diet-induced reduction, by increased lipid availability, of muscle glucose uptake similar to that seen in the insulin-stimulated state, with the resultant elevated circulating glucose acting to suppress $\mathrm{HGO}$ either by autoregulatory mechanisms [15] or through elevated insulin secretion. The elevation of circulating insulin in parallel with glycaemia in the animals not treated with STZ is consistent with a major role of insulin in the reduced $\mathrm{HGO}$ resulting from isolated fat diet treatment. However, the insulin data cannot account for the apparent reduction in basal HGO in the STZ/fat compared to the STZ/starch group and it may be that autoregulatory or other mechanisms may account for this. Regarding the fat-diet induced suppression of glucose clearance, it is apparent that this is not secondary to acutely increased availability of circulating NEFA. If increased lipid availability is responsible, it must be derived from other sources, possibly either circulating [16] or intramuscular [17] triglyceride which has been found in other diet-induced models of muscle insulin resistance.

The timing of insulin secretion is critical. Type 2 diabetes is characterized by a failure of early insulin release and a normal or even elevated second phase; the total insulin release in Type 2 diabetes being often similar to or greater than normal. Normalization of the deficient early phase with a very small amount of insulin has a marked beneficial effect on prandial glycaemia in humans [18]. In the present study, the STZ/starch group displayed marked prandial hyperglycaemia despite a nearly normal total insulin response. As with the human condition, however, the insulin response was sluggish and significantly impaired in the first $30 \mathrm{~min}$. By that time hyperglycaemia was established and the subsequent insulin response was insufficient to re-establish normoglycaemia. Here it is interesting to note the results of a recent study [19] which investigated the effects after 1 year of hemipancreatectomy in healthy human subjects (who were donors to relatives with Type 1 (insulin-dependent) diabetes). Although no indicators of insulin action were measured, oral glucose tolerance had deteriorated. The striking effect on the insulin response was a major failure of the early response (see Fig. 1 of reference 19 where the 20 min insulin increment to an oral glucose load 1 year after surgery is approximately $160 \mathrm{pmol} / \mathrm{l}$ compared to nearly $300 \mathrm{pmol} / \mathrm{l}$ before surgery). The nature of the particular pancreatic defect is not clear from these studies but the present rat model may be useful for the study of the human defect. 
Table 2. Glucose metabolic index ( $\left.\mathrm{Rg}^{\prime}\right)$ for the individual muscles and adipose tissues. Insulin-stimulated tissue-specific glucose uptake $\left(\mu \mathrm{mol} \cdot 100 \mathrm{~g}^{-1} \cdot \mathrm{min}^{-1}\right)$

\begin{tabular}{|c|c|c|c|c|}
\hline & Control/starch & Control/fat & STZ/starch & STZ/fat \\
\hline$n$ & 6 & 6 & 7 & 5 \\
\hline $\begin{array}{l}\text { Muscle } \\
\text { soleus } \\
\text { extensor digitorum longus } \\
\text { white gastrocnemius } \\
\text { red gastrocnemius } \\
\text { white quadriceps } \\
\text { red quadriceps } \\
\text { plantaris } \\
\text { diaphragm } \\
\text { heart }\end{array}$ & $\begin{array}{r}46.2 \pm 2.5 \\
12.5 \pm 1.5 \\
5.1 \pm 0.9 \\
26.4 \pm 3.9 \\
5.5 \pm 0.7 \\
41.7 \pm 6.8 \\
20.1 \pm 4.5 \\
67.3 \pm 7.3 \\
94 \pm 12\end{array}$ & $\begin{array}{r}37.7 \pm 5.1^{\mathrm{a}} \\
9.3 \pm 0.9^{\mathrm{a}} \\
3.6 \pm 0.9^{\mathrm{b}} \\
18.1 \pm 2.9^{\mathrm{b}} \\
3.8 \pm 0.9^{\mathrm{a}} \\
23.3 \pm 2.6^{\mathrm{b}} \\
10.5 \pm 1.3^{\mathrm{b}} \\
32.3 \pm 4.5^{\mathrm{b}} \\
101 \pm 19\end{array}$ & $\begin{array}{r}46.9 \pm 2.2 \\
13.9 \pm 1.2 \\
6.2 \pm 0.8 \\
30.3 \pm 3.7 \\
8.3 \pm 1.5 \\
38.1 \pm 6.3 \\
15.4 \pm 2.1 \\
67.2 \pm 8.1 \\
112 \pm 17\end{array}$ & $\begin{array}{c}37.6 \pm 6.1^{\mathrm{a}} \\
9.8 \pm 1.1^{\mathrm{b}} \\
3.2 \pm 0.4 \\
17.5 \pm 3.7^{\mathrm{b}} \\
5.3 \pm 1.1^{\mathrm{a}} \\
22.2 \pm 7.0^{\mathrm{b}} \\
8.9 \pm 1.6^{\mathrm{b}} \\
32.6 \pm 5.1^{\mathrm{b}} \\
105 \pm 13\end{array}$ \\
\hline $\begin{array}{l}\text { Adipose } \\
\text { white: epididymal } \\
\text { inguinal } \\
\text { subcutaneous } \\
\text { brown: interscapular }\end{array}$ & $\begin{array}{c}9.2 \pm 2.4 \\
6.6 \pm 2.2 \\
8.1 \pm 2.3 \\
209 \pm 33\end{array}$ & $\begin{array}{c}1.7 \pm 0.2^{\mathrm{b}} \\
1.2 \pm 0.2^{\mathrm{b}} \\
2.4 \pm 0.4^{\mathrm{b}} \\
36.8 \pm 11.8^{\mathrm{b}}\end{array}$ & $\begin{array}{r}10.3 \pm 2.3 \\
5.6 \pm 2.1 \\
11.1 \pm 3.7 \\
187 \pm 31\end{array}$ & $\begin{array}{r}1.6 \pm 0.3^{\mathrm{b}} \\
1.1 \pm 0.2^{\mathrm{b}} \\
1.7 \pm 0.1^{\mathrm{b}} \\
53.8 \pm 12.3^{\mathrm{b}}\end{array}$ \\
\hline
\end{tabular}

${ }^{a} p<0.05$ fat-fed $(n=11)$ compared to starch-fed $(n=13)$ rats, ${ }^{b} p<0.01$ fat-fed compared to starch-fed rats STZ $=$ streptozotocin treatment

The extent to which the groups in this study model stages in the development of hyperglycaemia and insulin resistance in human conditions is less clear now than it might have seemed in the immediate past. In light of recent experimental [13] and theoretical studies [14], the association between increased HGO and hyperglycaemia in mild human Type 2 diabetes should be regarded as a possible artifact of the tracer methodologies used to measure HGO. The two reports suggest that many of the studies which found such relationships have probably overestimated HGO to an extent proportional to the glycaemia. The present study shows that mild hyperglycaemia can result from a reduced rate of clearance of circulating glucose in the presence of a reduced rate of $\mathrm{HGO}$. The basal HGO under these conditions is presumably suppressed by the combination of mild hyperglycaemia and hyperinsulinaemia, although whether this represents a normal degree of suppression under these conditions is not clear from the basal study alone. However, as noted above the suppressive effect on HGO of the higher levels of insulin present in the euglycaemic clamp study was

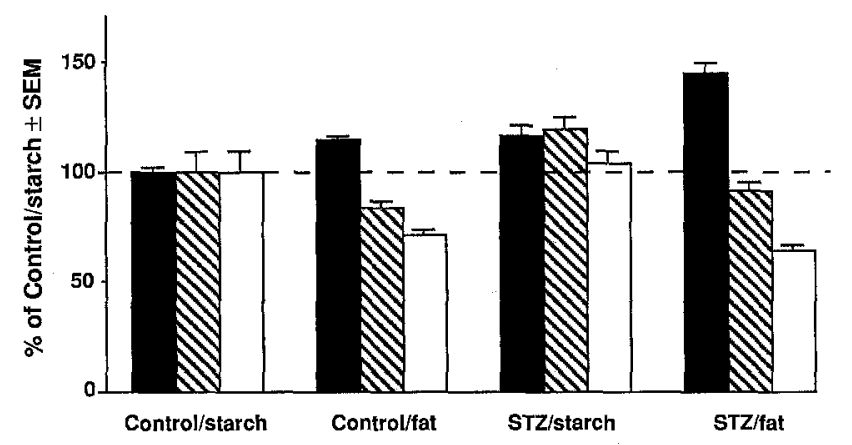

Fig. 7. Effect of high fat diet and/or streptozotocin (STZ) treatment on plasma glucose ( $\mathbf{v}$ ), basal glucose turnover ( $\mathbf{N})$, and basal glucose metabolic clearance rate $(\square)$. Results are expressed as percent of the value found in the control/starch group \pm SEM. Numbers of animals in each group for the three parameters are shown in Table 1 as are the statistical comparisons clearly reduced by fat feeding. It is therefore reasonable to conclude that the mild basal hyperglycaemia of the fat-fed group results from impairments in the control of both production and disposal of circulating glucose, and if so, it is noteworthy that this occurs when the absolute rate of basal HGO is reduced compared to the control group. If sufficiently accurate methods of measuring basal HGO in man can be applied to mild Type 2 diabetes, it is possible that a similar stage in the development of some (perhaps obese) Type 2 diabetic subjects could be identified. However such a finding need not imply the presence of a primary peripheral defect and more sophisticated study designs may be needed to assess the 'normality' of HGO control mechanisms.

The effects of STZ in the current model are easier to relate to current hypotheses regarding the development of hyperglycaemia and Type 2 diabetes in man. The neonatal STZ treatment and its resulting depletion of pancreatic insulin reserves and reduced secretory responses [1] clearly results in elevated basal HGO without effecting basal glucose clearance or glucose production and utilisation during the euglycaemic clamp. The relationships between basal insulin and glucose are at least reminiscent of the bell-shaped relationships seen in cross-sectional human studies [20] where above a critical glucose concentration there is a progressive failure of insulin secretion and a marked tendency towards severe hyperglycaemia. The present study supports the interpretation that in man a loss of adequate insulin secretion acts to produce hyperglycaemia mainly through removal of insulin suppression of the HGO.

In conclusion, these studies have identified the separate and combined effects of low-dose neonatal STZ treatment and fat feeding on glucose turnover which underlie the hyperglycaemic effects. Of particular note is the coexistence of hyperglycaemia and reduced basal $\mathrm{HGO}$ in the fat-fed groups even though the HGO suppression by elevated insulin is clearly impaired in the same groups. In addition, we have confirmed that widespread insulin resistance, both hepatic and peripheral, may be in- 
duced in these rats by feeding a high-fat diet. However, this insulin resistance does not appear to be exacerbated by relative insulin deficiency and/or hyperglycaemia - at least not after a 3-week feeding period. These direct measurements of insulin sensitivity confirm and extend relationships suggested in our previous study [1], regarding the interaction between insulin secretory abnormalities and insulin resistance. That is, the STZ/starch animal is able to maintain normal fasting glucose levels in the face of a marked reduction in insulin secretory capacity and a markedly reduced pancreatic insulin reserve because it has normal insulin sensitivity, while the STZ/fat animal becomes hyperglycaemic because the diminution of Betacell function is accompanied by loss of insulin sensitivity. In contrast, the control/fat animals maintains near normal glycaemia despite loss of insulin sensitivity, because it has normal insulin secretory capacity and a pancreatic insulin reserve greater than that of the STZ/fat animal.

Acknowledgements. The authors gratefully acknowledge the expert technical assistance of Ms. S. Mitchell. This work was supported by funds from the National Health and Medical Research Council (NH \& MRC) of Australia. WSP was the recipient of an NH \& MRC Biomedical Postgraduate Scholarship. Current address for Dr. Pascoe is the Max-Plank-Institut für Immunbiologie, Freiburg, FRG.

\section{References}

1. Pascoe WS, Storlien LH (1990) Inducement of basal hyperglycaemia in rats with abnormal $\beta$-cell function by fat-feeding: model for study of aetiology and pathogenesis of NIDDM. Diabetes 39: 226-233

2. Holman RR, Turner RC (1980) The basal plasma glucose: a simple relevant index of maturity-onset diabetes. Clin Endocrinol 14: 279-286

3. Zimmet P, Whitehouse S, Alford F, Chisholm D (1978) The relationship of insulin response to a glucose stimulus over a wide range of glucose tolerance. Diabetologia 15: 23-27

4. Halter JB, Graf RJ, Porte D Jr (1979) Potentiation of insulin secretory responses by plasma glucose levels in man: evidence that hyperglycaemia in diabetes compensates for impaired glucose potentiation. J Clin Endocrinol Metab 48: 946-954

5. Ward WK, Bolgiano DC, McKnight B, Halter JB, Porte D Jr (1984) Diminished $\beta$ cell secretory capacity in patients with noninsulin-dependent diabetes mellitus. J Clin Invest 74: 1318-1328

6. Portha B, Picon L, Rosselin G (1979) Chemical diabetes in the adult rat as the spontaneous evolution of neonatal diabetes. Diabetologia 17: 371-377

7. Kraegen EW, James DE, Jenkins AB, Chisholm DJ (1985) Doseresponse curves for in vivo insulin sensitivity in individual tissues in rats. Am J Physiol 248: E353-E362
8. Steele R, Watts JS, DeBodo RC, Altszuler N (1959) Measurement of size and turnover rate of body glucose pool by the isotope dilution method. Am J Physiol 187: 15-24

9. Hansen SA (1975) Thin-layer chromatographic method for identification of oligosaccharides in starch hydrozylates. J Chromatogr 105: 380-390

10. Morgan CR, Lazarow A (1963) Immunoassay of insulin. Two antibody system: plasma insulin levels of normal, subdiabetic and diabetic rats. Diabetes 12:115-126

11. Storlien LH, James DE, Burleigh KM, Chisholm DJ, Kraegen EW (1986) Fat feeding causes widespread in vivo insulin resistance, decreased energy expenditure and obesity in the rat. Am J Physiol 251: E576-E583

12. Kergoat M, Portha B (1985) In vivo hepatic and peripheral insulin sensitivity in rats with non-insulin-dependent diabetes induced by streptozotocin. Assessment with the insulin-glucose clamp technique. Diabetes 34: 1120-1126

13. Hother-Nielsen O, Beck-Nielsen H (1990) On the determination of basal glucose production rate in patients with Type 2 (non-insulin-dependent) diabetes mellitus using primed-continuous 3-3 $\mathrm{H}$-glucose infusion. Diabetologia 33: 603-610

14. Heath D (1990) Errors inherent in the primed infusion method for the measurement of the rate of glucose appearance in man when uptake is not forced by glucose or insulin infusion. Clin Sci 79: 201-213

15. Liljenquist JE, Mueller GL, Cherrington AD, Perry JM, Rabinowitz D (1979) Hyperglycaemia per se (insulin and glucagon withdrawn) can inhibit hepatic glucose production in man. J Clin Endocrinol Metab 48: 171-175

16. Thorburn AW, Storlien LH, Jenkins AB, Khouri S, Kraegen EW (1989) Fructose-induced in vivo insulin resistance and elevated plasma triglyceride levels in rats. Am J Clin Nutr 49: 1155-1163

17. Storlien LH, Jenkins AB, Chisholm DJ, Pascoe WS, Khouri S, Kraegen EW (1991) Influence of dietary fat composition on development of insulin resistance in rats: relationship to muscle triglyceride and $\omega-3$ fatty acids in muscle phospholipid. Diabetes 40: $280-289$

18. Bruce DG, Chisholm DJ, Storlien LH, Kraegen EW (1988) The physiological importance of the deficiency in early prandial insulin secretion in non-insulin dependent diabetes. Diabetes 37: 736-744

19. Kendall DM, Sutherland DER, Najarian JS, Goetz FC, Robertson RP (1990) Effects of hemipancreatectomy on insulin secretion and glucose tolerance in healthy humans. N Engl J Med 322: 898-903

20. DeFronzo RA (1988) The triumvirate: $\beta$-cell, muscle, liver. A collusion responsible for NIDDM. Diabetes 37: 667-687

Received: 13 August 1991

and in revised form: 23 October 1991

Dr. L. Storlien

Garvan Institute of Medical Research

St. Vincent's Hospital

Sydney, 2010

Australia 